Fourth International Conference on Sustainable Construction Materials and Technologies http://www.claisse.info/Proceedings.htm

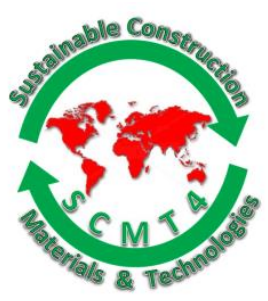

SCMT4

Las Vegas, USA, August 7-11, 2016

\title{
Effect of Sample Age on the Self-Healing Properties of Cementitious Materials with Superabsorbent Polymers
}

\author{
Didier Snoeck $^{1 a}$, and Nele De Belie ${ }^{1 b}$ \\ ${ }^{1}$ Magnel Laboratory for Concrete Research, Department of Structural Engineering, Faculty of \\ Engineering and Architecture, Ghent University, Technologiepark Zwijnaarde 904, 9052 Ghent, Belgium. \\ ${ }^{1 a}$ Email: <Didier.Snoeck@ugent.be>, ${ }^{1 b}$ Email: <Nele.DeBelie@ugent.be>.
}

\begin{abstract}
To obtain sustainable construction materials, occurring cracks in concrete should be repaired. However, as this often manual repair is time-consuming and expensive, self-healing may provide a solution. Autogenous healing is an already-present feature in cementitious materials, but it is an inferior mechanism as it can only heal cracks up to $30 \mu \mathrm{m}$ in the presence of water. Therefore, a cementitious material with synthetic microfibres and superabsorbent polymers (SAPs) is proposed. Synthetic microfibres cause multiple crack formation with small healable cracks. Furthermore, SAPs are able to extract moisture from the environment and to provide it to the cementitious matrix for autogenous healing. But, if the building blocks are exhausted in time due to ongoing hydration, healing may be less efficient. In this study, the ability of (promoted) autogenous healing in time ( 7 days, 28 days, 3 months and 1 year) is investigated by comparing the mechanical properties after performing four-point-bending tests in different mixtures. The specimens were first loaded to $1 \%$ strain, stored in wet/dry cycles for 28 days and were subsequently reloaded. The results show that, with increasing age, the crack width decreases and a higher water-to-binder ratio tends to increase the mean and maximum crack width. All specimens are able to heal and to regain some of the mechanical properties after being preloaded and precracked under four-point-bending. If SAPs are added, there is even healing in an environment without liquid water (relative humidity of more than 90\%). At early age, the healing is governed by further hydration and calcium carbonate crystallization. At later ages (after one month), the main autogenous healing mechanism is the formation of calcium carbonate crystals. The amount of white precipitated healing products was higher in specimens with a higher water-to-cement ratio. Cracks in the specimens with fly ash were better closed in comparison with the samples with pure cement and blast-furnace-slagblended mortars. Mixtures with SAPs showed more healing. The cementitious composite with microfibres and SAPs thus shows good self-healing in time.
\end{abstract}




\section{INTRODUCTION}

Cracking in concrete occurs commonly due to the relatively low tensile strength. However, concrete has a passive healing capacity of its own, also called autogenous healing. Generally, autogenous healing is ascribed to the following four healing mechanisms and their combination (Edvardsen, 1999; Granger et al., 2007; Homma et al., 2009; ter Heide, 2005):

i) further reaction of the hitherto unhydrated cement;

ii) closing of the cracks due to blocking by loose particles and impurities (inferior mechanism);

iii) expansion of the calcium-silicate-hydrate $(\mathrm{C}-\mathrm{S}-\mathrm{H})$ at the crack faces; and

iv) precipitation of calcium carbonate.

A recent review on synthetic microfibres autogenous healing and the application of superabsorbent polymers to stimulate this autogenous healing can be found in (Snoeck \& De Belie, 2015a). There are three needed conditions for autogenous crack healing to occur. These are the presence of specific building blocks $\left(\mathrm{Ca}^{2+}, \mathrm{CO}_{2}\right.$, etc.); the exposure to humid environmental conditions (wet/dry cycles, submersion in water, etc.) and restricted crack widths. Cracks in high-strength cementitious materials need to be small in order to be completely healable. If not, the products available in the mortar mix are consumed before the crack is effectively closed. However, a dedicated material design can promote the autogenous healing capacity. For the proposed material in this research, the $30 \mu \mathrm{m}$ criterion is most important. Two possible mechanisms and their combined effect are investigated in this study.

The first mechanism is the introduction of microfibres to obtain fibre-reinforced cementitious materials with a high tensile ductility, as studied by (Li, 2008; Yang, 2008). These composites exhibit tensile strainhardening behavior achieved by matrix multiple cracking. The studied material in this research is an ultraductile fibre-reinforced cementitious material optimized through the use of micromechanics in order to attain high tensile ductility and tight micro-cracks at moderate fibre contents. Due to the use of microfibres, the crack widths are restrained within the healable range $(30-50 \mu \mathrm{m}$ for complete healing after wet/dry cycles, smaller than the $150 \mu \mathrm{m}$ criterion for no healing (Yang, 2008; Yang et al., 2009)). But the healing is limited (as water needs to be present) and needs to be stimulated. In a humid environment, so without the presence of liquid water, the material indeed does not show any form of healing (Yang et al., 2009).

The second healing mechanism is the use of superabsorbent polymers (SAPs), improving/promoting the obtained autogenous healing capacity. SAPs have the ability to absorb a significant amount of liquid from the surrounding environment (up to 500 times their own weight) and to retain the liquid within their structure without dissolving. SAP particles swell due to the osmotic pressure difference between the hydrogel and the external solution. The use of SAPs to promote autogenous healing is dual. SAP particles swell due to mixing-water uptake during the mixing process and shrink during hardening of the cementitious material, leaving behind macro pores (Yao et al., 2011). These macro pores act as initial flaws and promote multiple cracking. Secondly, SAP-particles are very useful for autogenous healing as they absorb water during wet periods and slowly release it during dry periods. When liquids enter a crack, SAP particles along the crack faces will swell and block the crack. Also, as the SAPs swell, they will initially seal a crack from intruding fluids, thus increasing the durability (Lee et al., 2010a; Lee et al., 2010b). By absorbing fluids from the surroundings, water is also available for healing. The SAPs were thus added to further improve the autogenous healing (Snoeck \& De Belie, 2015b; Snoeck et al., 2014b).

The aim of the current research is to investigate the ability of SAPs to promote self-healing in microfibrereinforced concrete under realistic conditions of wet-dry cycles, and in air with medium or high relative humidity. In this way, a smart cementitious material which is reliable and less independent from external conditions will be acquired. 


\section{EXPERIMENTAL INVESTIGATION}

\section{Materials}

The studied mortar mixtures are composed of ordinary Portland cement (CEM I $52.5 \mathrm{~N}$ ), fly ash (Class F), fine quartz sand M34 $\left(\mathrm{D}_{50}=170 \mu \mathrm{m}\right)$, water, a polycarboxylate superplasticizer (Glenium 51, conc. $35 \%$ ), and $2 \mathrm{v} \%$ (volume percent) of polyvinyl alcohol fibres (15 dtex; $8 \mathrm{~mm}$ cutting length; $12 \mathrm{cN} / \mathrm{dtex}$ tenacity). In other mixtures, a varying amount of SAP expressed as mass-percentage $(0 / 0.5 / 1 \mathrm{~m} \%)$ of cement weight was added on top of the reference mixture without SAPs. Two different types of SAP were used. These include SAP A being a copolymer of acrylamide and sodium acrylate (particle size $100.0 \pm$ $21.5 \mu \mathrm{m}$ ), and SAP B a cross-linked potassium salt polyacrylate (particle size $477 \pm 53 \mu \mathrm{m}$ ). Both SAPs are bulk-polymerized and consist of irregular crushed particles. Additional water was used to compensate for the loss in workability. To find the most-ideal mixture for autogenous healing, some parameters were varied. These were the replacement of cement by fly ash $(\mathrm{FA} / \mathrm{C}=0 / 0.5 / 1)$ or blast-furnace slag $(\mathrm{BFS} / \mathrm{C}=$ $0 / 0.5 / 1)$. The sand-to-binder $(\mathrm{S} / \mathrm{B}=0.35)$ and superplasticizer content $(\mathrm{Spl} / \mathrm{B}=0.0097)$ was kept constant. The water-to-binder ratio was varied as well $(\mathrm{W} / \mathrm{B}=0.30 / 0.35 / 0.40)$. Those varying parameters should give the most information and influences in terms of autogenous healing as a function of the composition. The most ideal mixture was selected and used to study the influences of superabsorbent polymers. This ideal mixture had a $\mathrm{FA} / \mathrm{C}=1$ and $\mathrm{W} / \mathrm{B}=0.30$ factor. The compositions (with superabsorbent polymers where applicable) are shown in Table 1. 'REF' states a mixture without SAPs, '0.5A/0.5B/1B' a mixture with $0.5 \mathrm{~m} \%$ SAP A and SAP B and $1 \mathrm{~m} \%$ of SAP B, respectively.

Table 1. Mortar composition of the most ideal mixture [ $\left.\mathrm{kg} / \mathrm{m}^{3}\right]$; C stands for cement, and FA, S, W, Spl and PVA for fly ash, sand, water, superplasticizer and PVA fibres, respectively. The water content is divided to show the amount of additional water $\mathbf{W}_{\text {add }}$.

\begin{tabular}{|l|l|l|l|l|l|l|l|l|}
\hline$\left[\mathrm{kg} / \mathrm{m}^{3}\right]$ & $\mathrm{C}$ & $\mathrm{FA}$ & $\mathrm{S}$ & $\mathrm{W}+\mathrm{W}_{\text {add }}$ & Spl & PVA & SAP A & SAP B \\
\hline REF & 608 & 608 & 426 & 365 & 11.8 & 26 & - & - \\
\hline $0.5 \mathrm{~A}$ & 554 & 554 & 388 & $332+85$ & 10.7 & 26 & 2.77 & - \\
\hline $0.5 \mathrm{~B}$ & 590 & 590 & 413 & $354+26$ & 11.4 & 26 & - & 2.95 \\
\hline 1B & 572 & 572 & 400 & $343+51$ & 11.1 & 26 & - & 5.72 \\
\hline
\end{tabular}

The first step in the mixing procedure was dry mixing of cement, fly ash and possibly SAPs (depending on the mixture composition) with a standard mortar mixer for $30 \mathrm{~s}$ until they were equally distributed. Water and superplasticizer were then added to the dry mixture and it was mixed during $30 \mathrm{~s}$ at $140 \mathrm{rpm}$. The fine silica sand was next added and the composition was again mixed during $30 \mathrm{~s}$ at $140 \mathrm{rpm}$. To ensure a homogeneous dispersion of all components, the speed was increased for the following $30 \mathrm{~s}$ to $285 \mathrm{rpm}$. The edges of the bowl were scraped during 30 seconds and there was a resting period of $60 \mathrm{~s}$. Subsequently, at a speed of $140 \mathrm{rpm}$, microfibres were slowly added during $30 \mathrm{~s}$. The final step was mixing for $60 \mathrm{~s}$ at $285 \mathrm{rpm}$. Moulds $\left(160 \times 40 \times 10 \mathrm{~mm}^{3}\right.$ samples $)$ were filled and the samples were compacted by jolting 60 times. The samples were demoulded after 24 hours and were stored at a relative humidity of $95 \pm 5 \%$ and a temperature of $20 \pm 2{ }^{\circ} \mathrm{C}$ until an age of 7, 28 days, 3 months and 1 year. Series used within this study, consisted of minimally three samples.

Four-point-bending test. Fibre-reinforced composites exhibit multiple-cracking behavior, and this was examined using a four-point-bending test. Series used for four-point bending tests, consisted of minimally three $160 \times 40 \times 10 \mathrm{~mm}^{3}$ samples with $2 \mathrm{v} \%$ of polyvinyl alcohol (PVA) fibres. By means of a four-pointbending test, multiple cracks were created in the mortar prisms at an age of 7, 28 days, 3 months and 1 year. The cracking occurred under standard laboratory conditions at a relative humidity of $60 \%$. The 
servo-hydraulic testing system (Walter+Bai DB 250/15) ensured a displacement-controlled test $(0.0015 \mathrm{~mm} / \mathrm{s}$ to imitate a quasi-static load). The displacement was increased until $1 \%$ strain at the bottom of the specimen.

After cracking, the samples were cured for 28 days under three conditions:

i) wet/dry cycles during which samples were stored alternately for one hour in water and 23 hours in air at a $\mathrm{RH}$ of $60 \%$ and $20 \pm 2^{\circ} \mathrm{C}$;

ii) at a relative humidity of more than $90 \%$ and $20 \pm 2{ }^{\circ} \mathrm{C}$, and;

iii) at a relative humidity of $60 \%$ and $20 \pm 2{ }^{\circ} \mathrm{C}$.

After a period of 28 days, the specimens were tested again in four-point-bending and the mechanical properties (first-cracking-strength) obtained during the first and the second loading cycle were compared. The self-healing capacity was determined as the regain of the first-cracking-strength after reloading the specimens until complete failure.

\section{RESULTS AND DISCUSSIONS}

Multiple cracks needed to be created and an amount of $2 \mathrm{v} \%$ of PVA is sufficient to show a pronounced amount of multiple cracking and strain-hardening. When a crack forms, PVA fibres will bridge a crack and due to fibre-bridging action, the stress can still increase until the weakest part of the bridging fibre does not manage to take up the additional forces. The stress keeps augmenting until a previously created crack widens, lowering the stress. This leads to a substantial amount of cracks and thus ductility. In specimens loaded until total failure, sometimes more than 15-20 cracks were formed, showing the high ductility. This is an inherent feature of the pronounced strain-hardening found when using synthetic microfibres.

All cracks were through-going, which is typical for steady-state cracks which are formed when performing four-point-bending tests on mixtures with incorporated synthetic microfibres. The crack width did not vary significantly over the total crack length and all microscopic properties were similar. By microscopically studying these cracks, the crack widths could be determined. Most important is the range of crack widths (mean value) and the largest crack. The latter is important as that crack width is mostly the limiting factor for the regain in mechanical properties. If there is one large crack compared to the other cracks, this crack will preferentially open even if the other cracks are ideally and perfectly sealed and healed by healing products.

Different mixtures were first studied; Portland cement mixtures, mixtures with fly ash or blast-furnace slag and a different water-to-binder ratio. All studied mixtures can be found in (Snoeck, 2015). With increasing age, the crack width decreases in all mixtures. This is due to the stronger cementitious matrix with time due to hardening and thus the more fibre-pull-out force needed, leading to the lower pull-out length of the separate fibres and thus lower crack width. This was also found in literature (Kan \& Shi, 2012; Yang et al., 2011). The differences between the mixtures are mainly due to the differences in matrix properties. The differences in crack width are not significant, but sometimes a lower crack width is found in fly-ash systems. The blast-furnace slag mixtures tend to show a higher mean crack width compared to the cement references and the fly-ash mixtures. A higher water-to-binder ratio tends to increase the mean and maximum crack width. This is likely due to the less-strong cementitious matrix. An even lower water-to-binder ratio was not workable and a higher water-to-binder ratio led to segregation of the mixture which was also unwanted. Most of the mixtures are within the wanted $30 \mu \mathrm{m}$ crack width boundary to show optimal autogenous-healing opportunities, if loaded till $1 \%$ of strain. 
The number of cracks and the strain in the cracked zone are closely related. The higher the ductility, the better is the possible autogenous-healing capacity. The highest ductility is found when cracking the specimens at an age of 7 days, and decreases with increasing age. This is due to the hardening of the cementitious matrix in time, reducing the ductile capacity. This is mainly due to the stronger matrix, influencing the crack-tip and strength criterion to obtain strain-hardening cementitious materials. With increasing water-to-binder ratio, the amount of multiple cracking (and number of cracks) decreases. This is due to the change in strength criterion. A lower water-to-binder ratio is thus wanted. This lower ratio is also more preferential and beneficial in terms of autogenous healing as more building blocks will be available upon crack formation. Using fly ash increases the multiple-cracking behavior. This is due to the smaller and rounder shape of the fly ash, increasing the self-compacting properties and the strainhardening behavior. An even higher amount of fly ash would decrease this property. Replacement of part of the cement by blast-furnace slag also tends to increase this multiple-cracking ductility but is not optimal for a water-to-binder ratio of 0.30 , but rather at 0.35 . The highest ductility is found in the mixture with $\mathrm{FA} / \mathrm{C}=1$ and $\mathrm{W} / \mathrm{B}=0.30$.

The influence of the age on the strength criterion to obtain a strain-hardening cementitious material is also reflected in the value of the first-cracking-strength. The strength increases in time during hardening, which is logical. All strength values are within the same range and are typical values for strain-hardening cementitious materials (Li, 2008; Yang, 2008; Yang et al., 2007; Yang et al., 2009) (see Table 2 later-on). The regain in mechanical properties, in this case the first-cracking-strength, when storing specimens in wet/dry cycles is dependent on the age of the specimen. The older the specimen, the lower is the regain in mechanical properties. This is due to the further hydration and stiffening of the cementitious matrix in time. This leads to a lower amount of available building blocks for the autogenous-healing mechanisms. The amount of healing also tends to decrease with increasing water-to-binder ratio, but the differences are not statistically significant. Again, this reduces the amount of available building blocks as less unhydrated particles remain within the cementitious matrix. However, using fly ash and blast-furnace slag, increases the amount of regain in mechanical properties. The pozzolanic reaction by the fly ash and the latenthydraulic reaction of the blast-furnace slag seem promising for the autogenous healing. Fly ash continues to hydrate after 28 days, and the hydrated products may heal the cracks, increasing the self-healing ability. This was also found by (Jacobsen et al., 1995; Termkhajornkit et al., 2009; Zhou et al., 2011). In the long term, $\mathrm{Ca}(\mathrm{OH})_{2}$ may not exist anymore due to the well-progressed pozzolanic reaction and carbonation, explaining the lower regain in mechanical properties at later ages as the pozzolanic reaction slows down.

At early age there is further hydration combined with calcium-carbonate crystallization and from 3 months onwards, the main healing mechanism is the precipitation of $\mathrm{CaCO}_{3}$. This was also seen in literature (Van Tittelboom et al., 2012). The amount of white precipitated healing products was higher in specimens with a higher water-to-cement ratio. This is due to the higher amount of available $\mathrm{Ca}(\mathrm{OH})_{2}$ which is used for the $\mathrm{CaCO}_{3}$ precipitation. This is the case in the reference samples and the samples with fly ash. The samples with blast-furnace slag are the other way around. A remark can be made. The matrix is composed out of $\mathrm{C}-\mathrm{S}-\mathrm{H}, \mathrm{CH}$ and alkali oxides. If more $\mathrm{C}-\mathrm{S}-\mathrm{H}$ is formed, the $\mathrm{pH}$ value is expected to decrease, especially when high amounts of fly ash are available in the composite and $\mathrm{Ca}(\mathrm{OH})_{2}$ is consumed. The formation of $\mathrm{CaCO}_{3}$ could hereby be limited (due to the reduced $\mathrm{pH}$ level). This was not the case in the studied mixtures in this research. The $\mathrm{pH}$ value of the intruding fluid inside a crack is dependent on the fluid composition itself rather than the mixture composition. In time, the leaching out of products may change the $\mathrm{pH}$-value. The specimens with fly ash closed their cracks better in comparison with the samples with pure cement and blast-furnace-slag-blended mortars. Better visual healing is achieved with a lower water-to-cement ratio and with fly ash. Some examples of the healing through further hydration, calcium carbonate crystallization and their combined effect are shown in Figure 1. 


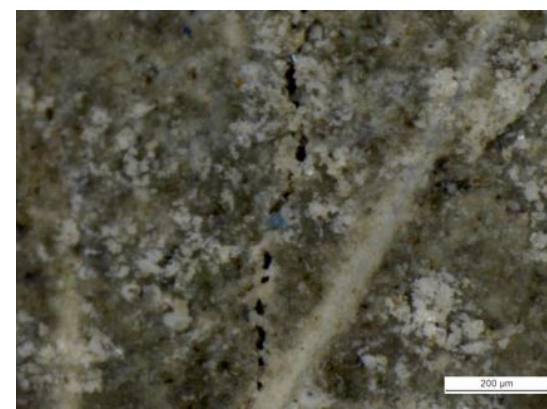

(a)

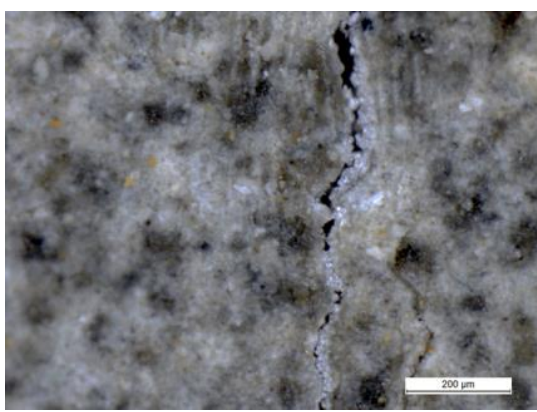

(b)

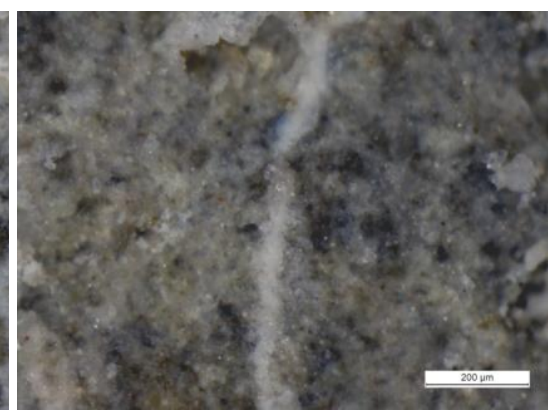

(c)

Figure 1. Autogenous healing through further hydration (a), calcium carbonate crystallization (b) and their combined mechanism (c).

The best overall mixture (considering all aspects) was the mixture with $\mathrm{FA} / \mathrm{C}=1$ and $\mathrm{W} / \mathrm{B}=0.30$ and this mixture was studied in detail in different curing conditions (Table 2). It possesses a high strain-hardening effect and small healable cracks. Superabsorbent polymers were also included and their effects were studied in great detail. Important properties are the strength and the regain in strength of the cementitious materials with and without superabsorbent polymers.

Table 2. Mean values and standard deviations for the crack width $[\mu \mathrm{m}]$, the first-crackingstrength [MPa], and the regain in first-cracking-strength [\%] with their respective standard deviations on single results $(n=3)$.

\begin{tabular}{|c|c|c|c|c|c|c|c|c|c|c|c|}
\hline \multirow[b]{3}{*}{ REF } & \multirow{6}{*}{$\begin{array}{l}7 \text { days } \\
28 \text { days } \\
3 \text { months } \\
1 \text { year }\end{array}$} & \multirow{2}{*}{\multicolumn{2}{|c|}{$\begin{array}{l}\text { Crack } \\
\text { width } \\
{[\mu \mathrm{m}]}\end{array}$}} & \multirow{2}{*}{\multicolumn{2}{|c|}{$\begin{array}{c}\text { First- } \\
\text { cracking- } \\
\text { strength } \\
{[\mathrm{MPa}]}\end{array}$}} & \multicolumn{6}{|c|}{ Regain in first-cracking-strength [\%] } \\
\hline & & & & & & \multicolumn{2}{|c|}{ wet/dry cycles } & \multicolumn{2}{|c|}{$R H>90 \%$} & \multicolumn{2}{|c|}{$R H=60 \%$} \\
\hline & & $24 \pm 12$ & $\mathbf{0}$ & $4.5 \pm 0.3$ & ש & $59 \pm 9$ & 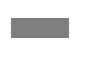 & $7 \pm 2$ & $\mathbf{I}$ & $1 \pm 1$ & \\
\hline & & $20 \pm 11$ & 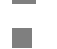 & $4.8 \pm 0.6$ & ש & $45 \pm 7$ & ש & $7 \pm 1$ & $\mathbf{I}$ & $1 \pm 1$ & 1 \\
\hline & & $16 \pm 10$ & 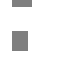 & $5.4 \pm 0.5$ & ש & $42 \pm 5$ & m & $7 \pm 1$ & $\mathbf{I}$ & $1 \pm 1$ & । \\
\hline & & $11 \pm 7$ & 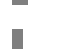 & $6.0 \pm 0.5$ & ש & $35 \pm 6$ & a & $6 \pm 1$ & $\mathbf{I}$ & $0 \pm 1$ & \\
\hline \multirow[t]{4}{*}{$0.5 \mathrm{~A}$} & 7 days & $23 \pm 10$ & $\mathbf{a}$ & $4.9 \pm 0.4$ & ש & $74 \pm 9$ & ש & $49 \pm 7$ & ש & $27 \pm 6$ & $\mathbf{\square}$ \\
\hline & 28 days & $18 \pm 10$ & 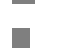 & $4.9 \pm 1.5$ & D & $65 \pm 2$ & 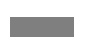 & $51 \pm 3$ & ש & $29 \pm 9$ & 口 \\
\hline & 3 months & $16 \pm 9$ & 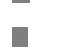 & $5.3 \pm 2.2$ & ש & $59 \pm 2$ & $\mathbf{m}$ & $46 \pm 2$ & m & $28 \pm 9$ & 口 \\
\hline & 1 year & $10 \pm 6$ & I & $5.6 \pm 2$ & = & $45 \pm 1$ & E & $33 \pm 3$ & ש & $19 \pm 4$ & - \\
\hline \multirow[t]{4}{*}{$0.5 \mathrm{~B}$} & 7 days & $22 \pm 10$ & $\mathbf{\square}$ & $4.6 \pm 0.5$ & m & $72 \pm 4$ & m & $58 \pm 5$ & m & $33 \pm 2$ & ש \\
\hline & 28 days & $19 \pm 11$ & 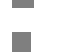 & $5.1 \pm 1.1$ & ש & $69 \pm 3$ & ש & $54 \pm 3$ & ש & $35 \pm 7$ & $\mathbf{m}$ \\
\hline & 3 months & $17 \pm 9$ & 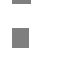 & $5.2 \pm 1$ & = & $65 \pm 6$ & ( & $44 \pm 2$ & ש & $26 \pm 2$ & - \\
\hline & 1 year & $11 \pm 8$ & 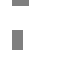 & $5.5 \pm 2$ & = & $53 \pm 2$ & m & $44 \pm 5$ & m & $21 \pm 4$ & - \\
\hline \multirow[t]{4}{*}{$1 \mathrm{~B}$} & 7 days & $21 \pm 9$ & च & $4.7 \pm 0.4$ & E & $87 \pm 6$ & ש & $61 \pm 4$ & ש & $45 \pm 8$ & E \\
\hline & 28 days & $21 \pm 10$ & $\square$ & $4.9 \pm 0.9$ & & $86 \pm 8$ & 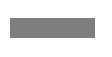 & $64 \pm 8$ & 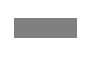 & $44 \pm 2$ & ש \\
\hline & 3 months & $13 \pm 10$ & 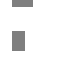 & $5.3 \pm 1.8$ & ש & $81 \pm 8$ & D & $62 \pm 9$ & 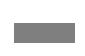 & $43 \pm 3$ & a \\
\hline & 1 year & $12 \pm 6$ & 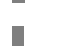 & $5.5 \pm 1.3$ & (0 & $65 \pm 5$ & 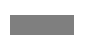 & $54 \pm 3$ & ש & $32 \pm 2$ & 口 \\
\hline
\end{tabular}


To study the regain in mechanical properties, the strain at the bottom of the specimen was limited to $1 \%$. All specimens in this study showed four to five cracks when loaded to $1 \%$ strain. The crack width was hereby always limited to $30 \mu \mathrm{m}$ in all specimens, which is ideal for autogenous healing. Not only are cracks able to visually close, the composite is able to regain some of its mechanical properties. All results are shown in Table 2. In this table, the crack width, first-cracking-strength and the regain in firstcracking-strength in the three different storage conditions are given. The three storage conditions are storage in wet/dry cycles ( 1 hour in water and 23 hours in standard laboratory conditions), at a relative humidity of more than $90 \%$ and at a relative humidity of $60 \%$. The temperature was always $20 \pm 2{ }^{\circ} \mathrm{C}$ and the healing period was 28 days.

The mean crack widths are not statistically significant from each other between the different mixtures and decrease with age. This is due to the hardening of the cementitious matrix as explained before. Superabsorbent polymers do not have an influence on the properties of the cementitious matrix when additional water is used; they only facilitate multiple cracking and the cracks are alike. This is a strong positive influence to receive a high regain in mechanical properties and this is even further improved by using SAPs. Air voids - and thus also SAP macro pores - act as crack initiators, so the crack path likely follows the position of macro pores. The SAPs are thus available for swelling upon crack formation as the crack runs through the formed pore.

With increasing age, the building blocks will become exhausted. This will also lead to a lower amount of autogenous healing as the healing relies on the amount of unhydrated cement particles, $\mathrm{Ca}(\mathrm{OH})_{2}$, unhydrated parts of the pozzolanic fly ash and the amount of leachable $\mathrm{Ca}^{2+}$ ions present in the matrix. As already found previously, the healing mechanism changes in time due to the changing availability of building blocks. At early age, more further hydration will occur but later-on, the calcium-carbonate crystallization will govern the overall healing. At an age of 7 days and 28 days of healing, the self-healing mechanism is mostly the stitching of the crack by further hydration and calcium carbonate around SAPs. In samples with an age of 28 days, there is a little bit more $\mathrm{CaCO}_{3}$ in the crack. With a sample age of 3 months onwards, there is mainly $\mathrm{CaCO}_{3}$ on the crack faces. New formed cracks seem strong enough and sometimes new cracks are formed, or cracks follow other pathways than the previously formed and healed cracks.

The first-cracking-strength of the different test series cracked at 7 days and stored at different healing conditions for 28 days can be compared. No significant differences exist between the stress values measured for samples with and without SAPs. SAPs have a dual effect on the strength (Hasholt et al., 2012; Snoeck et al., 2014a). On one hand they will increase the strength due to the further hydration by the release of mixing water in time during hardening of the cementitious matrix (i.e. due to internal curing). But, on the other hand, they will decrease the strength due to the formation of macro pores. Both influences combined leads in this case to an equivalent first-cracking-strength in these strain-hardening mixtures with a low water-to-binder ratio. Overall, the strength is not significantly different between all studied samples. The amounts of SAPs were limited to $0.5 \mathrm{~m} \%$ and $1 \mathrm{~m} \%$ in case of SAP A and SAP B, respectively. These amounts did not induce a decrease in mechanical properties. Higher amounts of SAPs would result in a decrease in initial mechanical properties.

After cracking, the specimens were stored in several curing conditions to study the effects on autogenous healing in mixtures with and without SAPs. In the meantime, the specimens were thus microscopically monitored in time. By microscopically studying the crack before and after the healing, the amount of autogenous healing products could be quantified. It was found that cracks up to $30 \mu \mathrm{m}$ were able to close complete in wet/dry cycles. This $30 \mu \mathrm{m}$ criterion is more severe compared to the $50 \mu \mathrm{m}$ criterion found in literature (Yang et al., 2009). SAPs have an additional effect on the healing capacity as their water is released steadily to the cementitious matrix during dry periods. Even cracks up to $138 \mu \mathrm{m}$ were able to 
close completely. This is mainly due to the crystallization of $\mathrm{CaCO}_{3}$. The microfibres themselves are also useful to promote autogenous healing as they serve as a nucleation site for $\mathrm{CaCO}_{3}$ crystals, as also seen by (Homma et al., 2009).

The regain in mechanical properties is certainly noticed in wet/dry cycles where abundant water is available for the autogenous healing mechanisms of further hydration and calcium-carbonate crystallization. Storage in an environment with a relative humidity of more than $90 \%$ only showed partial visual closure of cracks for samples containing SAPs. SAP particles manage to take moisture out of a humid environment and provide it to the cementitious matrix for crack healing. Also cracks of specimens stored at a relative humidity of $60 \%$ only healed if the samples contained SAPs. This is similar to internal curing and is reflected in regained first-cracking-strength. The reference samples without superabsorbent polymers are expected to show no regain in mechanical properties in a moist environment as no water will be present to induce autogenous healing. This was also seen in previous investigations of (Yang, 2008).

Reference samples in wet/dry cycles show a regain of about $45 \%$, which is comparable to values found in literature of $40 \%$ (Yang et al., 2009) and 42\% (Yang, 2008). The incorporation of SAPs in this investigation, however, promotes self-healing in air of sufficient relative humidity. The samples with SAPs do show a regain in strength when stored in a relative humidity of more than $90 \%$. The moisture uptake by SAPs (up to four times their own weight in moisture seems to be sufficient to promote a certain degree of autogenous healing, especially in the interior of the crack in the form of further hydration. In the relative humidity condition of more than $90 \%$, the material with $1 \mathrm{~m} \%$ SAP B shows a strength regain of $60 \%$. In those specimens, further hydration occurred, leading to the regain in mechanical properties. At the crack mouth, the crack was still clearly open and only at some distinct places, there was some bridging of a crack by healing products. At reloading, previously created cracks reopened and no new cracks were formed until all cracks reopened. Newly formed cracks were only seen when the specimens were stored in wet/dry cycles.

A higher amount of SAPs, without decreasing the strength, leads to a higher amount of promoted autogenous healing due to more steadily-available water in time. Using $1 \mathrm{~m} \%$ SAP B leads to a regain of $80-90 \%$ in wet/dry cycles and sometimes, a new crack is formed instead of the reopening of a healed crack, which shows a total regain of the mechanical properties at that distinct place. In the interior mostly further hydration occurred and more pronounced $\mathrm{CaCO}_{3}$ crystals mixed together with hydration products were formed at the crack mouth. The best combined result considering the mechanical properties and the healing capacity in all curing conditions is obtained by using $1 \mathrm{~m} \%$ SAP B relative to the cement weight.

\section{CONCLUSION}

Micro-fibre reinforced strain-hardening cementitious materials are durable and provide reliable tensile ductility and crack-controlling capability to prevent localized cracking failure often observed in concrete structures. Their small cracks are interesting in terms of autogenous healing where only small cracks are able to heal completely. At early age ( 7 days), the main healing mechanism is the stitching of a crack by further hydration. After an age of 28 days more calcium carbonate is seen, and after 3 months of age (and even up to 1 year of age), this calcium carbonate crystallization is the main healing mechanism.

The best overall self-healing mixture had a fly-ash-to-cement ratio of 1 , a sand-to-binder ratio of 0.35 , a water-to-binder ratio of 0.30 , a superplasticizer-to-binder ratio of 0.0097 and $2 \mathrm{v} \%$ of oil-coated PVA microfibres. 
Superabsorbent polymers are beneficial as they can promote autogenous healing by release of their absorbed water upon crack formation and this leads to a regain in mechanical properties. SAPs can sustain hydration by yielding their absorbed water for further hydration and for the precipitation of calcium carbonate. When not completely submerged in water, only samples containing SAPs showed self-healing properties due to moisture uptake. The amount of healing increased in following order:

\section{REF RH $>90 \%<$ SAP RH $=60 \%<$ SAP RH $>90 \%<$ REF wet/dry < SAP wet/dry}

Introducing $1 \mathrm{~m} \%$ of SAP B relative to the cement weight gives the best results, considering no decrease in overall mechanical properties of the virgin material, which are similar as for the reference, and the superior self-healing capacity.

SAPs can be useful in regions with almost no rain, or for structures not exposed to direct rainfall, because they absorb moisture and provide it to the cementitious matrix for healing. In regions with wet/dry cycles, water remains present in the SAPs during the dry periods. Therefore, self-healing can prevail at all times. Generally, the overall healing and closure of a crack may lead to less ingress of potentially harmful substances, thus possibly increasing the durability and service life of civil structures. This feature is enhanced due to the swelling action of the superabsorbent polymers and the subsequent better crystallization in a crack.

\section{ACKNOWLEDGEMENTS}

As a Research Assistant of the Research Foundation-Flanders (FWO-Vlaanderen), D. Snoeck wants to thank the foundation for the financial support.

\section{REFERENCES}

Edvardsen, C. (1999). Water Permeability and Autogenous Healing of Cracks in Concrete. ACI Materials Journal, 96(4), 448-454.

Granger, S., Loukili, A., Pijaudier-Cabot, G., \& Chanvillard, G. (2007). Experimental characterization of the self-healing of cracks in an ultra high performance cementitious material: Mechanical tests and acoustic emission analysis. Cement and Concrete Research, 37(4), 519-527.

Hasholt, M.T., Jensen, O.M., Kovler, K., \& Zhutovsky, S. (2012). Can superabsorbent polymers mitigate autogenous shrinkage of internally cured concrete without compromising the strength? Construction and Building Materials, 31, 226-230.

Homma, D., Mihashi, H., \& Nishiwaki, T. (2009). Self-Healing Capability of Fibre Reinforced Cementitious Composites. Advanced Concrete Technology, 7(2), 217-228.

Jacobsen, S., Marchand, J., \& Hornain, H. (1995). SEM observations of the microstructure of frost deteriorated and self-healed concrete. Cement and Concrete Research, 25(8), 55-62.

Kan, L., \& Shi, H. (2012). Investigation of self-healing behavior of Engineered Cementitious Composites (ECC) materials. Construction and Building Materials, 29, 348-356.

Lee, H.X.D, Wong, H.S., \& Buenfeld, N.R. (2010a). Self-sealing cement-based materials using superabsorbent polymers. Paper presented at the International RILEM Conference on Use of Superabsorbent Polymers and Other New Additives in Concrete, Lyngby.

Lee, H.X.D., Wong, H.S., \& Buenfeld, N.R. (2010b). Potential of superabsorbent polymer for self-sealing cracks in concrete. Advances in Applied Ceramics, 109(5), 296-302. 
Li, V.C. (2008). Engineered Cementitious Composites (ECC) - Material, Structural, and Durability Performance. In E. Nawy (Ed.), Concrete Construction Engineering Handbook (pp. 78): CRC Press.

Snoeck, D. (2015). Self-Healing and Microstructure of Cementitious Materials with Microfibres and Superabsorbent Polymers. Doctor in Civil Engineering: Construction Design, Ghent University, Ghent.

Snoeck, D., \& De Belie, N. (2015a). From straw in bricks to modern use of microfibres in cementitious composites for improved autogenous healing - a review. Construction and Building Materials, 95, 774-787.

Snoeck, D., \& De Belie, N. (2015b). Repeated autogenous healing in strain-hardening cementitious composites by using superabsorbent polymers. Journal of Materials in Civil Engineering, 04015086, $1-11$.

Snoeck, D., Schaubroeck, D., Dubruel, P., \& De Belie, N. (2014a). Effect of high amounts of superabsorbent polymers and additional water on the workability, microstructure and strength of mortars with a water-to-cement ratio of 0.50. Construction and Building Materials, 72, 148-157.

Snoeck, D., Van Tittelboom, K., Steuperaert, S., Dubruel, P., \& De Belie, N. (2014b). Self-healing cementitious materials by the combination of microfibres and superabsorbent polymers. Journal of Intelligent Material Systems and Structures, 25(1), 13-24.

ter Heide, N. (2005). Crack Healing in Hydrating Concrete. Delft University of Technology, Delft.

Termkhajornkit, P., Nawa, T., Yamashiro, Y., \& Saito, T. (2009). Self-healing ability of fly ash-cement systems. Cement and Concrete Composites, 31(3), 195-203.

Van Tittelboom, K., Gruyaert, E., Rahier, H., \& De Belie, N. (2012). Influence of mix composition on the extent of autogenous crack healing by continued hydration or calcium carbonate formation. Construction and Building Materials, 37, 349-359.

Yang, E.-H. (2008). Designing added functions in Engineered Cementitious Composites. University of Michigan, Ann Arbor.

Yang, E.-H., Yang, Y., \& Li, V.C. (2007). Use of High Volumes of Fly Ash to Improve ECC Mechanical Properties and Material Greenness. ACI Materials Journal, 104(6), 303-311.

Yang, Y., Lepech, M.D., Yang, E.-H., \& Li, V.C. (2009). Autogenous Healing of Engineered Cementitious Composites under Wet-dry Cycles. Cement and Concrete Research, 39(5), 382-390.

Yang, Y., Yang, E.-H., \& Li, V.C. (2011). Autogenous healing of engineered cementitious composites at early age. Cement and Concrete Research, 41(2), 176-183.

Yao, Y., Zhu, Y., \& Yang, Y. (2011). Incorporation of SAP particles as controlling pre-existing flaws to improve the performance of ECC. Construction and Building Materials, 28(1), 139-145.

Zhou, Z.H., Li, Z.Q., Xu, D.Y., \& Yu, J.H. (2011). Influence of Slag and Fly Ash on the Self-Healing Ability of Concrete. Advanced Materials Research, 306-307, 1020-1023. 